\title{
Genetically Modified Organisms. Importance in the current world.
}

\author{
Organismos genéticamente modificados. Importancia en el mundo actual.
}

Nelson Santiago Vispo

DOI. 10.21931/RB/2018.03.01.1

\section{$T$}

he concept of sustainable development is the basis of a wide variety of international and national policies. The world population continues to expand 80 million people per year while the demand for natural resources continues to increase. Policies, treaties, and important goals underpin the notion of sustainable development. In this document, we discuss and test a variety of scientific literature related to the use of transgenic crops to achieve sustainable development objectives ${ }^{1}$.

There is a lot of pressure to not only expand the list of transgenic crops, and the percentage of their uses but also adding the possibility of marketing genetically modified animals. The main problem with the use of transgenic products is that, at present, the consequences of their consumption in humans in the short and long term are not really known. The use of genetically modified organisms (GMOs) increases companies' profits since the size of the plants can be greater (as the pests do not affect the crops are much larger and more abundant, etc.).

There are increasingly voices that demand not the elimination of these products, but rather more exhaustive and rigorous analyzes that ensure that they do not affect, or affect, the human being in the immediate future.

\section{Lets discuss then how GMO arise}

Horizontal gene transfer (HGT) is the movement of genetic material between unicellular and/or multicellular organisms, which is not through vertical transmission (the transmission of DNA from parents to their offspring). It was first described in the 40 in microorganisms and 20 years later it has shown that it has a fundamental role in the adaptation to the environment of eukaryotic organisms, specifically in plants².

The first rule in horizontal gene transfer seems to be to produce no damage, the genes that are integrated into the genome of another organism related or not, are often expressed at low levels and code for functions at the periphery of the host organism metabolism. However, these neutral acquisitions can provide novel combinations of genetic material so that natural selection can choose the best-adapted organisms. Sometimes, the transferred material evolves and produces a beneficial phenotype. In other cases, when the imported genes remain neutral and there is no obvious benefit associated with their retention, they are likely to be lost over time ${ }^{3}$.

Mankind has been altering the genomes of plants and animals for many years using traditional breeding techniques. Artificial selection for the desired specific traits has resulted in a variety of different organisms, ranging from the most pest-resistant corn to the different breeds of pets. But this artificial selection, in which organisms that exhibit specific traits are chosen to engender later generations, has been limited to natural variations. In recent decades, however, advances in the field of genetic engineering have allowed precise control over the genetic changes introduced into an organism. Today, we can incorporate new genes from one species into a completely unrelated species through recombinant DNA techniques, optimizing agricultural yield or facilitating the production of valuable pharmaceutical substances. Farming plants, farm animals, and soil bacteria are some of the most prominent examples of organisms that have undergone genetic engineering ${ }^{4}$.

After the successful expression of the first recombinant proteins in bacteria and yeast, it became evident that numerous human proteins could not be produced efficiently using such systems because human proteins do not undergo post-translational modifications in bacterial cells, and The nature of the modifications in the yeast cells is different from those that take place in human cells such as for example glycosylation patterns. Furthermore, these expression systems cannot guarantee adequate folding of a series of human proteins, therefore, the research community faced the challenge of developing alternative expression systems capable of guaranteeing correct post-translational modifications. A simultaneous development of two technological models (based on transgenic animals and cultures of mammalian cells) was initiated giving, as a result, the first successful production of transgenic mammals ${ }^{5}$.

The first successful production of transgenic mammals by the microinjection of genetically modified constructs in the pronucleus of a mouse zygote was carried out more than 20 years ago $^{6}$. In the US market UU for 2012, a total of 193 products were obtained using cultures of mammalian cells. This has been largely attributed to the fact that it was not until 2006 that the European Agency for the Evaluation of Medicines (EMEA) approved antithrombin, the first recombinant protein derived from the milk of transgenic goats. This protein was later approved for commercialization by the United States Food and Drug Administration (FDA) as a medicine that prevents blood clotting in patients with hereditary antithrombin deficiency. In 2011, the EMEA approved the use of the recombinant cl-esterase inhibitor produced in rabbits for the treatment of hereditary angioedema. The arrival on the market of the first therapeutic products produced with transgenic animals and their approval for medical use suggest that recombinant proteins could forge an important niche in biotechnology in the near future?

Agricultural plants are one of the most cited examples of GMOs. Some benefits of genetic engineering in agriculture translate into higher yields, lower costs of food or drug production, less need for pesticides, higher nutrient composition, food quality, resistance to pests and diseases, greater food security and benefits doctors for the growing world population. Advances have also been made in the development of crops that mature faster and tolerate aluminum, boron, salt, iron, drought, frost and other environmental stressors, allowing plants to grow in conditions where they would not bloom. Several animals have also been genetically modified to increase yield and decrease susceptibility to disease. For example, salmon and tilapia have been designed to grow and mature faster and cattle have been improved to show resistance to mad cow disease ${ }^{8}$. 
Figure 1. By Keith Weller, USDA - This image was released by the Agricultural Research Service, the research agency of the United States Department of Agriculture, with the ID K7743-13 (next)., Public Domain, https://commons.wikimedia.org/w/index. php?curid=185217

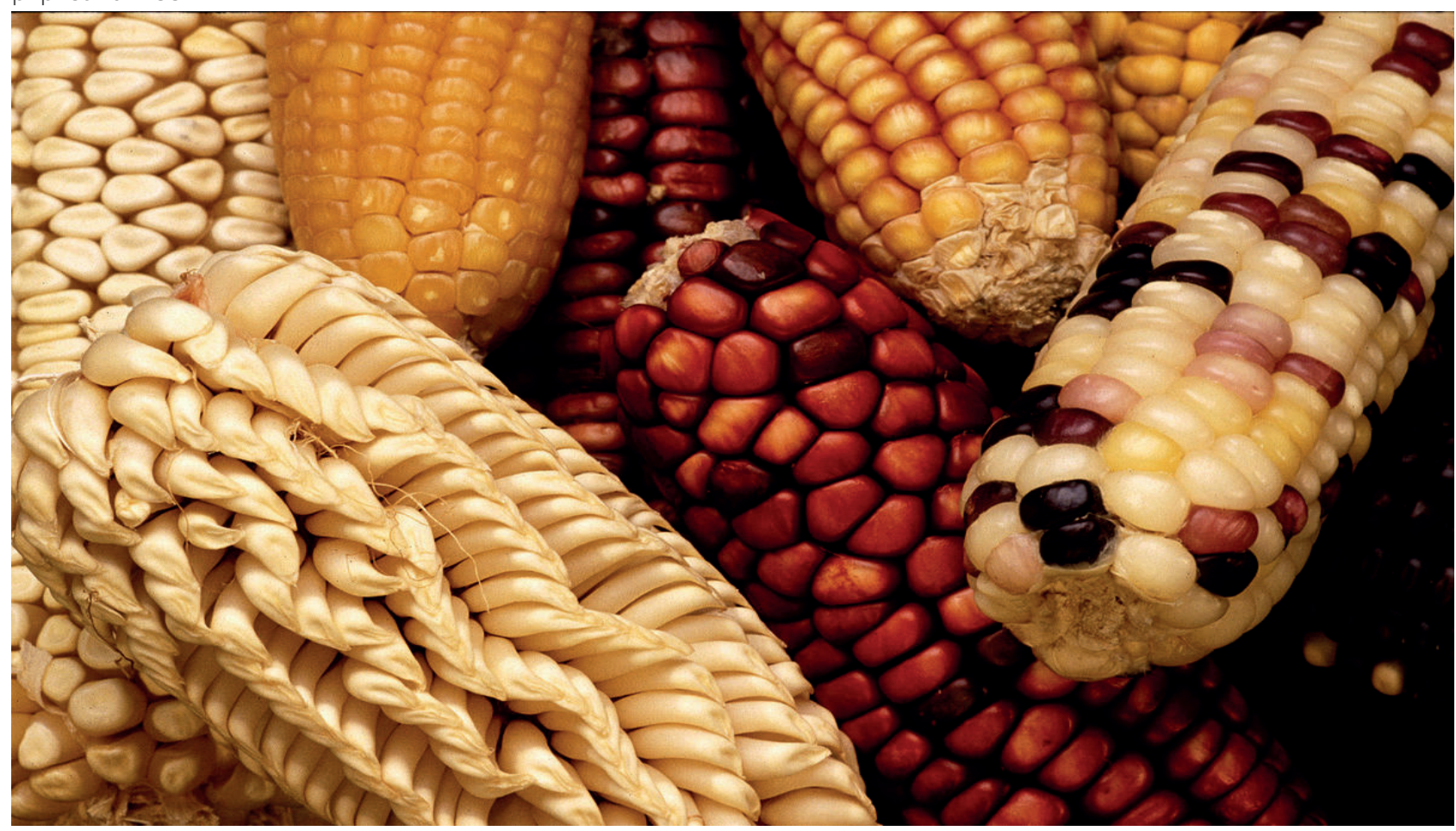

The aquatic environment is connected to the surrounding agricultural landscapes, which regularly serve as sources of stressors such as agrochemicals. Genetically modified crops, which are grown on a large scale in many countries, can also act as stressors. Despite the commercial use of GMOs for over 20 years, its impact on the aquatic environment was only 10 years ago. The analysis of effects studies reveals that only a narrow range of organisms has been tested and that studies on the combinatorial actions of stressors are practically absent. The analysis of the destination studies shows that many aspects, such as the fate of leached toxins, the degradation of plant materials and the distribution of crop residues in the aquatic habitat, are not sufficiently investigated. Along with these research needs, we identify the standardization of test methods as a matter of high priority, both for research and for the evaluation of risks necessary for the regulation of $\mathrm{GMOs}^{9}$.

\section{History of international regulations for GMO research and development}

In 1971, the first debate about the risks to humans of exposure to GMOs began when a common intestinal microorganism, E. coli, became infected with DNA from a tumor-inducing virus ${ }^{10}$. Initially, safety issues were a concern for people working in laboratories with GMOs, and for nearby residents. However, the subsequent debate arose out of concern that recombinant organisms could weapons. The growing debate, restricted to scientists, eventually spread to the public, and in 1974, the National Institutes of Health $(\mathrm{NIH})$ established the Recombinant DNA Advisory Committee to address some of these problems.

In the 1980s, when deliberate releases of genetically modified organisms took place in the environment, the United States had few regulations in force. Adherence to the guidelines provided by the $\mathrm{NIH}$ was voluntary for the industry. Also during the 1980s, the use of transgenic plants was becoming a valuable effort for the production of new pharmaceutical products, and individual companies, institutions, and countries saw biotechnology as a lucrative means of earning money. The worldwide commercialization of biotechnological products generated a new debate on the patentability of living organisms, the adverse effects of exposure to recombinant proteins, questions of confidentiality, the morality and credibility of scientists, the role of government in regulating science and other matters. In the USA the initiatives of the Technology Assessment Office of Congress were developed, which were adopted throughout the world as a top-down approach to advice policymakers in predicting the social impacts of GMOs.

Then, in 1986, a publication of the Organization for Economic Cooperation and Development (OECD), called "Recombinant DNA Security Considerations," became the first intergovernmental document to address issues related to the use of GMOs. This document recommends that risk assessments should be carried out on a case-by-case basis. Since then, the case-by-case approach for risk assessment for genetically modified products has been widely accepted; however, the USA they have generally adopted a product-based evaluation approach, while the European approach is more process-based. Although in the past there was a lack of comprehensive regulation in many countries, governments around the world now meet public demands and apply more stringent testing and labeling requirements for genetically modified crops ${ }^{11,12}$

In Ecuador, the commercialization of foods with transgenic content is restricted. The regulations apply both to products that come from abroad and to those that are made throughout the nation. Current regulations not only regulate their commercialization, but they also prohibit the experimentation, production, and cultivation of these organisms. The Ecuadorian Constitution, in its Article 14, states that the use of genetically modified organisms (transgenic) is prohibited since they harm human health and undermine food sovereignty. The restrictions on these organisms in Ecuador dates from 1999 when under the government of former 
Figure 2. By International Rice Research Institute (IRRI) [CC BY 2.0 (https://creativecommons.org/licenses/by/2.0)], via Wikimedia Commons

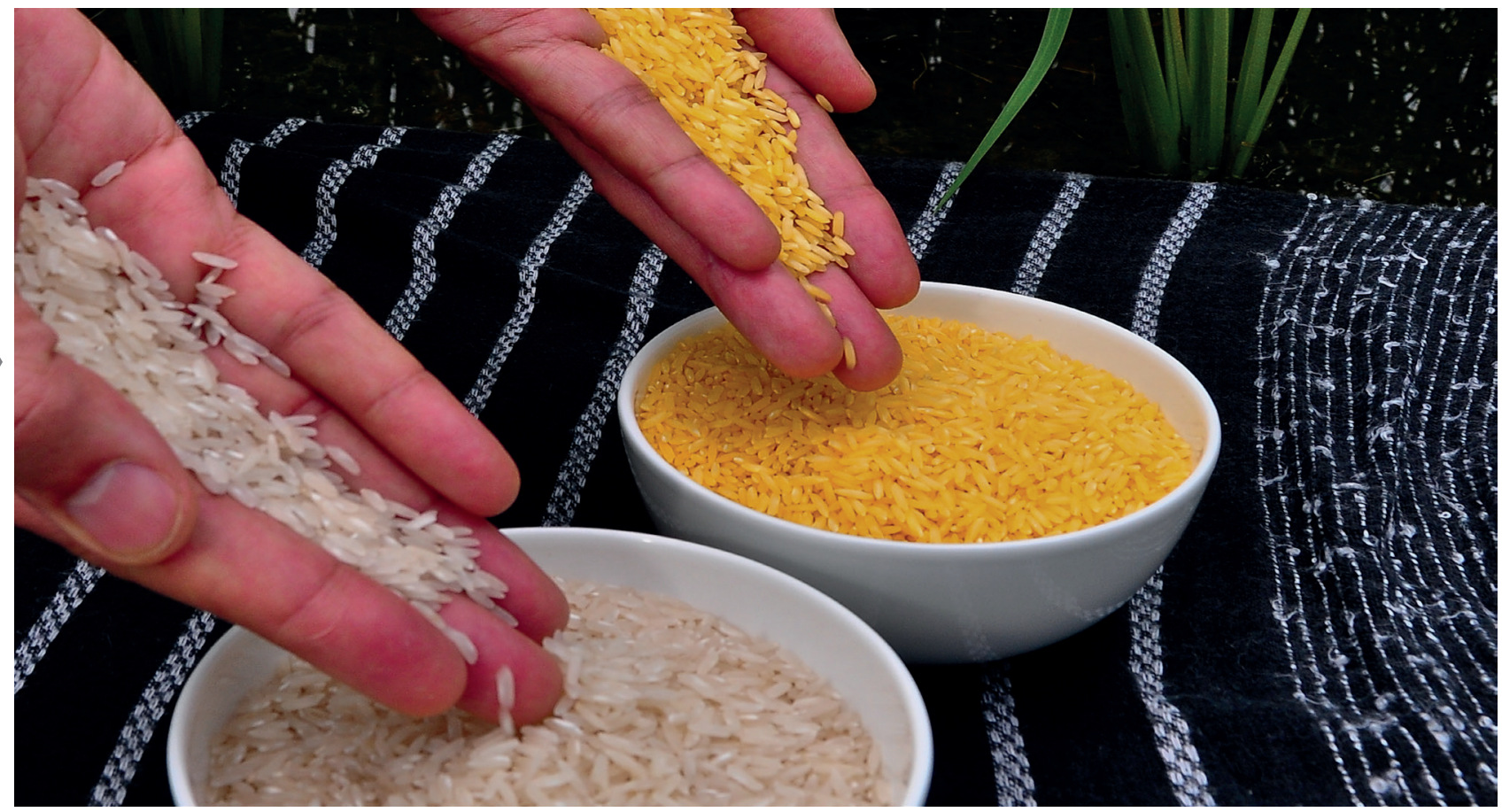

President Jamil Mahuad, these regulations were established. Faced with this legal impediment, the only way to access these products was through imports. On August 18, 2000, through the Health Registration and Control Regulation, it was specified that only transgenic products with the approval of the Ministry of Health could enter the country ${ }^{13}$. That same year, through the Organic Law of Consumer Protection, the right of access to information on a transgenic product is established. The legal body stated: "If the products for human consumption or livestock to be commercialized have been obtained or improved through gene transplantation or in general genetic manipulation, this fact shall be noted on the product label, in highlighted letters." From this background, Ecuadorian laws have restricted the production and commercialization of transgenic through different regulations that have reinforced this intention over the last two decades ${ }^{14}$.

\section{Increased research and improved security go hand in hand}

Advocates of the use of GMOs believe, with proper research, these organisms can be traded safely. There are many experimental variations in the expression and control of modified genes that can be applied to minimize potential risks. Some of these practices are already necessary as a result of new legislation, such as avoiding the transfer of superfluous DNA (vector sequences) and replacing the selectable marker genes commonly used in the laboratory (antibiotic resistance) with harmless markers derived from plants ${ }^{12}$

Issues such as no differentiating between the GMO and the regular plant could be overcome by incorporating identification factors, such as pigmentation, that facilitate the tracking and separation of genetically modified products from non-genetically modified products. Other incorporated control techniques include having inducible promoters (eg, stress-induced, chemicals, etc.), geographic isolation, using sterile male plants and separate growth stations ${ }^{4}$.

\section{Conclusions}

A considerable amount of evidence has accumulated since the first commercial crop of transgenic based products, suggesting that they can contribute to the three traditional pillars of sustainability, economics, environment, and society. As the world population continues to rise, the evidence reviewed here suggests that it would be unwise to ignore GMO crops as one tool that can help meet aspirations for sustainable global development.

GMOs benefit humanity when used for purposes such as increasing the availability and quality of food and medical care and contributing to a cleaner environment. If used wisely, they could improve the economy without causing more harm than good, and they could also take advantage of its potential to ease hunger and disease around the world. However, the full potential of GMOs cannot be realized without due diligence and attention to the risks associated with each new GMO on a case-by-case basis.

\section{Bibliographic references}

1. United Nations Development Programme (UNDP). Background of the Sustainable Development Goals I UNDP. 2017.http:// www.undp.org/content/undp/en/home/sustainable-development-goals/background.html (accessed 17 May2018).

2. Swithers KS, Soucy SM, Gogarten JP. The Role of Reticulate Evolution in Creating Innovation and Complexity. Int J Evol Biol 2012; 2012: 1-10.

3. Soucy SM, Huang J, Gogarten JP. Horizontal gene transfer: Building the web of life. Nat Rev Genet 2015; 16: 472-482.

4.Phillips BT, Write PD, Right S, Education N. Genetically Modified Organisms ( GMOs ): Transgenic Crops and Recombinant DNA Technology. 2014; : 1-7.ew targeted treatments for non-small cell lung cancer. Mol Oncol. 2009 Dec;3(5-6):409-24. 
5. Yuan CL, Hu Y-C. A Transgenic Core Facility's Experience in Genome Editing Revolution. Springer, Cham, 2017, pp 75-90.

6. Stewart CL, Vanek M, Wagner EF. Expression of foreign genes from retroviral vectors in mouse teratocarcinoma chimaeras. EMBO J 1985; 4: 3701-9.

7. Maksimenko OG, Deykin a V, Khodarovich YM, Georgiev PG. Use of transgenic animals in biotechnology: prospects and problems. Acta Naturae 2013; 5: 33-46.

8. Human Genome Project Information. https://web.ornl.gov/sci/ techresources/Human_Genome/index.shtml (accessed 17 May2018).

9. Pott A, Otto M, Schulz R. Impact of genetically modified organisms on aquatic environments: Review of available data for the risk assessment. Sci Total Environ 2018; 635: 687-698.

10. Devos Y, Maeseele P, Reheul D, Speybroeck L, Waele D. Ethics in the societal debate on genetically modified organisms: $\mathrm{A}(\mathrm{Re})$ quest for sense and sensibility. J Agric Environ Ethics 2008; 21 : 29-61.

11. Takeda S, Matsuoka M. Genetic approaches to crop improvement: responding to environmental and population changes. Nat Rev Genet 2008; 9: 444-457.

12. Ma JK-C, Drake PMW, Christou P. Genetic modification: The production of recombinant pharmaceutical proteins in plants. Nat Rev Genet 2003; 4: 794-805

13. Asamblea constituyente 2008: art. 1. Constitución Del Ecuador. Const del Ecuador 2008; : 218.

14. Congreso Nacional. Ley Orgánica De Defensa Del Consumidor. 2014 